Flávia Biroli

\title{
Mídia, tipificação e exercícios de poder: a reprodução dos estereótipos no discurso jornalístico
}

Há uma conexão entre nossa visão e os fatos, mas é com frequência uma estranha conexão. (Walter Lippmann, Opinião pública)

Estereótipos e mídia aparecem juntos em muitas análises e comentários sobre o funcionamento da mídia nas sociedades contemporâneas ${ }^{1}$. Mas é comum que não exista mais, nesse caso, do que co-habitação, isto é, que sua presença simultânea nas análises não corresponda a um esforço para estabelecer uma relação entre os termos e, sobretudo, para esclarecer de que natureza é essa relação.

O entendimento do que define os estereótipos, e de como circulam e produzem efeito, pode ser, nesse caso, apenas um desdobramento da compreensão que se tem do funcionamento dos meios de comunicação. Assim, se esses últimos são vistos como responsáveis por um ambiente comunicativo rico, em que informações e visões de mundo diversas e conflitantes passam a fazer parte da vivência dos indivíduos, eles trabalhariam, em linhas gerais, contra a manutenção dos estereótipos. Mas se os meios de comunicação são vistos como instrumentos de uma ordem social desigual, reproduzindo

\footnotetext{
A discussão apresentada neste artigo é parte do projeto "Gênero e política na mídia brasileira", coordenado pela autora e financiado pelo CNPq (edital 57/2008, bolsas de PQ e IC). Ela contou com o levantamento de dados e literatura teórica feitos pelo bolsista de Iniciação Científica Pedro de Mesquita Santos, a quem agradeço. Agradeço, também, a Luis Felipe Miguel pelos comentários críticos a uma versão anterior deste artigo, que foram fundamentais para a organização dos argumentos nesta versão. A posição aqui sustentada e, especialmente, suas falhas são, é claro, de inteira responsabilidade da autora.
} 
informações e visões homogêneas que confirmam as perspectivas dominantes, eles poderão ser vistos como propagadores privilegiados dos estereótipos. Trabalhariam, nesse caso, a favor da reprodução de estereótipos que justificam ou são uma espécie de "caldo de cultura" da própria dominação.

Não pretendo aqui mapear a menção aos estereótipos em análises da mídia que não são propriamente voltadas para o problema da relação entre mídia, estereótipos e exercícios de poder. Mas é útil caminhar um pouco, ainda, com a distinção feita acima, sobretudo porque ela nos permite expor brevemente uma compreensão dual, em que o foco está na superação dos estereótipos ou na sua reprodução.

A primeira das duas visões pode ser associada, historicamente, à correspondência entre conhecimento e razão. As informações, e melhor dizendo, a multiplicação das informações - e das opiniões - disponíveis seria a base para a superação dos preconceitos associados aos estereótipos. Haveria uma correlação positiva entre a quantidade e a variedade das informações disponíveis e a possibilidade de superação das visões distorcidas ou estereotípicas da vida social. De maneira pouco sistemática, seria possível estabelecer conexões entre essa compreensão e debates clássicos que associam a livre circulação de ideias e opiniões ao avanço em direção à verdade (pode-se pensar no Areopagítica, de John Milton, de 1644, ou no Sobre a liberdade, de John Stuart Mill, publicado pela primeira vez em 1859). Mas essa ponte não expressa parte importante do que estaria presente nas análises contemporâneas: os avanços técnicos são vistos como um fator central à ampliação das informações disponíveis. Eles teriam modificado não apenas a quantidade, mas também a qualidade das interações e das formas de sociabilidade na medida em que permitem o contato dos indivíduos, a partir de sua situação e contexto, com uma gama ampla e múltipla de realidades e vivências.

No campo dos estudos de mídia, as análises de Joshua Meyrowitz (1985) sobre o impacto dos meios de comunicação para a sociabilidade contemporânea podem ser consideradas representativas desse entendimento. Para ele, a difusão massiva permitida pelos avanços técnicos ampliaria, potencialmente, o acesso a imagens e valores diferentes daqueles que organizam o ambiente presencial dos indivíduos. E isso se daria, até certo ponto, independentemente de quais são os conteúdos veiculados. A comunicação mediatizada, mais do que a interpessoal, colocaria os indivíduos em contato com opiniões e experiências diferentes das suas (Mutz e Martin, 2001), permitindo o compartilhamento 
de referências alternativas para a compreensão de seu papel social. Nesse argumento, as transformações na mídia, com o advento da mídia eletrônica, correspondem a transformações nos papéis sociais. A fusão de "mundos informacionais" diferentes encorajaria, entre outras coisas, formas mais igualitárias de interação (Meyrowitz, 1985, p. 64), incidindo diretamente sobre as identidades de grupo, as formas e etapas de socialização e as hierarquias.

$\mathrm{Na}$ segunda das visões aqui consideradas sobre a relação entre mídia e estereótipos, aquela que destaca o papel dos meios de comunicação de massa como propagadores dos estereótipos, o que ganha saliência é, diferentemente, a relação entre a mídia e o exercício da dominação, ou entre a comunicação midiatizada e a reprodução da hegemonia. Os estereótipos aparecem como uma dimensão da imposição, pelos grupos e estratos de grupos dominantes, de sua visão de mundo. E a mídia aparece como um instrumento central de sua propagação. Nesse caso, a relação entre conhecimento e superação dos preconceitos fica comprometida pelo fato de que o controle das informações e mesmo a produção da verdade (do que é assim apresentado e poderá ser assim percebido) estão no centro da dinâmica de dominação. Um de seus aspectos é a propagação de representações unilaterais e homogêneas da realidade, apresentadas como sendo a própria realidade ou o que importa dela. Também aqui, pode-se remeter à tradição liberal, mas de outra perspectiva: é a relação entre verdade e opinião que faz da primeira o objeto das disputas (Nascimento, 1989). A disputa ideológica corresponderia, então, justamente a uma disputa por definir o que é a verdade em um contexto em que existe diversidade de opiniões e informações. Por isso, seu sucesso depende da transformação de opiniões "parciais" em representações "universais" e supostamente unitárias da realidade.

O fato de que a mídia coloca em circulação um grande número de informações é, portanto, insuficiente para que se afirme que potencializa uma constelação plural de representações da vida social. É insuficiente, também, para que se estabeleça um vínculo direto entre disponibilidade de informações e superação dos preconceitos e estereótipos relacionados a grupos sociais específicos. É preciso avaliar a partir de que perspectivas sociais são selecionadas as informações relevantes, em que representações (parciais) da realidade elas ganham sentido. Os estereótipos não são, necessariamente, uma peça-chave nas análises da mídia assim orientadas. Mas a visão tipificada da realidade social, e especialmente os estereótipos dos grupos e indivíduos desigualmente 
posicionados em uma dada ordem social, participaria da naturalização dos arranjos e hierarquias existentes e da contenção da crítica a eles.

Assim, a mídia difundiria os estereótipos e, dada sua centralidade na construção do ambiente social contemporâneo, colaboraria desse modo para sua naturalização, confirmando cotidianamente determinadas visões de mundo, em detrimento de outras. Parte ampla da crítica feminista aos vieses de gênero na mídia pode ser considerada como um exemplo dessa visão. Isso se dá, sobretudo, quando as análises enfocam a naturalização do pertencimento da mulher à esfera privada e dos arranjos familiares que o justificam e reforçam ${ }^{2}$, assim como o destaque dado ao corpo e à aparência física das mulheres ${ }^{3}$. Mas é possível, também, associar a essa vertente análises voltadas para problemas de outra ordem, como o impacto da socialização dos jornalistas dentro e fora das redações para a percepção que têm do que é notícia, de quais atores merecem ser ouvidos na cobertura noticiosa, e a que atividades e competências esses atores estão associados ${ }^{4}$.

É necessário ressaltar que a mídia é importante para as duas visões aqui indicadas - o pressuposto de que a mídia tem um papel na superação dos estereótipos e o pressuposto de que tem um papel na sua reprodução e naturalização a colocam, igualmente, numa posição-chave nas disputas pela representação do mundo social. Mas isso não significa que as análises avancem, necessariamente, na reflexão sobre a dinâmica social de produção e reprodução dos estereótipos e sobre sua relação com o funcionamento dos meios de comunicação.

Este artigo procura justamente contribuir para que essa reflexão avance. Ele foi suscitado por pesquisas empíricas sobre a presença de mulheres no noticiário político e está, como tal, geneticamente ligado à problemática dos estereótipos de gênero 5 . Há aqui, no entanto, um esforço para discutir

\footnotetext{
Um exemplo interessante é a análise da mídia estadunidense nos anos 1950, especialmente das revistas produzidas para o público feminino, feita por Betty Friedan em The feminine mystique (1997 [1963]).

3 Em textos menos centrados na mídia, como o de Naomi Wolf (2002 [1991]) ou preocupados, de fato, com o impacto da mídia para as relações de gênero e a participação das mulheres na política, como em Miguel e Biroli (2011) ou em Kahn (1996).

4 O pertencimento dos jornalistas a uma classe média branca levaria à identificação com alguns grupos sociais e problemas (em análises distintas, como as de Schudson, 1995, p. 8; Ettema e Glasser, 1998; ou Miguel e Biroli, 2010), assim como o ambiente profissional os levaria a perceber a política a partir da posição privilegiada daqueles que se tornam suas fontes (Cook, 1998).

5 Para resultados da pesquisa "Determinantes de gênero, visibilidade midiática e carreira política no Brasil", conferir Miguel e Biroli (2011). Outros diálogos entre a pesquisa empírica sobre a presença de mulheres no noticiário político e a reflexão sobre os estereótipos de gênero podem ser encontrados em Biroli (2010; 2011).
} 
a relação entre mídia e estereótipos sem focar, especificamente, no gênero - ainda que as questões que o concernem continuem a fornecer exemplos que são relevantes para a sustentação dos argumentos apresentados. A ideia é que a análise colabore também para estudos que tratem de outros aspectos da relação entre mídia e estereótipos, considerando outros grupos sociais ou questões mais amplas, relativas à definição da agenda e dos enquadramentos na mídia.

Pelos caminhos indicados nesta introdução, e que serão desdobrados no artigo, chegamos a um argumento central: parece necessário colocar em suspenso a dualidade entre mídia/superação dos estereótipos e mídia/ propagação dos estereótipos, para que seja possível chegar a uma forma mais complexa e matizada de compreensão da relação entre mídia, estereótipos e exercícios de poder. $\mathrm{O}$ artigo procura dar esse passo.

A análise que daí resulta está organizada em duas seções, além desta introdução e de uma breve conclusão. A primeira discute o conceito de estereótipo, propondo que seja compreendido como artefato moral e ideológico. A segunda apresenta uma reflexão teórica sobre as relações entre mídia e estereótipos, procurando indicar qual é o lugar ocupado pelos estereótipos na produção jornalística e como ele se vincula às narrativas cristalizadas (ou aos enquadramentos) que organizam o noticiário. A conclusão, por fim, baseia-se nas seções anteriores para propor um modo de compreensão do funcionamento da mídia na dinâmica social de produção, reprodução e superação dos estereótipos.

\section{Estereótipos, codificação e poder}

Nesta seção, o conceito de estereótipos é discutido levando em consideração seu potencial de interpelação, isto é, sua participação na constituição das identidades dos indivíduos e dos grupos. Assim, em primeiro lugar, procuramos considerar - e afastar - um entendimento que reduz os estereótipos a distorção, falsidade ou irrealidade. Essa posição nos leva, então, a considerar os estereótipos como categorias simplificadoras ou atalhos cognitivos que participam dos exercícios de poder. Mas, também aqui, foi preciso considerar matizes. A relação entre estereótipos e opressão não está, como será visto, livre de ambiguidades.

Uma das compreensões correntes na literatura define os estereótipos como dispositivos cognitivos que facilitam o acesso a novas situações e informa- 
ções. São simplificações que permitem a previsibilidade (Newman, 1975, p. 207). Equivalem a padrões que correspondem às expectativas normativas sobre os comportamentos dos atores numa dada sociedade e, nesse sentido, remetem diretamente aos papéis socialmente definidos (Goffman, 2008 [1963]). Consistem, portanto, em categorias que estabelecem padrões de aproximação e de julgamento, orientando a leitura do que é ou se apresenta como novo a partir de referências prévias. É nesse sentido que reduziriam a complexidade das interações concretas, contribuindo para ampliar o grau de previsibilidade nas novas interações: fundados em simplificações, os estereótipos diminuem as variações e matizes presentes nas trajetórias e comportamentos individuais, que se definem e se explicitam em interações e contextos sociais específicos.

Há diferenças significativas entre o entendimento dos estereótipos como esquemas simplificadores e sua definição como representações falsas da realidade. O entendimento dos estereótipos como distorção e falsidade pressupõe que exista uma fronteira bem delineada entre a estereotipia e a própria realidade. Isto é, as simplificações colocadas em curso pelos estereótipos estariam em contradição com a realidade de fato, que aqui poderíamos tomar, provisoriamente, como algo equivalente à vivência concreta dos indivíduos e grupos sociais quando afastada de imagens equivocadas. Dito de outra forma, entender que os estereótipos são distorções equivale a vê-los como uma espécie de nuvem de fumaça que impede o acesso à realidade, mas que, ainda que fique impregnada por algum tempo aos objetos, poderá ser afastada.

Quando se entende, diferentemente, que os estereótipos estão na base das representações da realidade que são internalizadas pelos indivíduos, orientando suas ações, a fronteira entre o falseamento e a realidade se torna no mínimo mais complexa. Mesmo que eles estejam fundados em padrões normativos que sejam considerados, de uma posição dada, desvantajosos para aqueles que são tipificados, eles não são exteriores à vivência concreta dos indivíduos. E ainda que sejam fantasias ou simplificações equivocadas - "as mulheres são maternais" - podem estar na base das identidades e dos papéis sociais e, portanto, constituir uma realidade bastante palpável e que tem impacto sobre o modo como as relações afetivas e de poder se organizam. Os estereótipos têm um caráter produtivo, naturalizando e realizando valores e julgamentos. 
Nesse sentido, seria preciso considerar que os estereótipos não correspondem a representações posteriores à dinâmica em que as identidades sociais se definem. Eles não poderiam, portanto, ser reduzidos a um fenômeno que deturpa modos de ser (caráter, personalidade, disposições individuais) que existiriam de maneira prévia porque são, eles mesmos, parte dos processos sociais de definição de papéis e reprodução dos valores. Os estereótipos participam da dinâmica social na qual se definem caráter, personalidade e disposições individuais.

A vivência das relações sociais fornece os recursos para a construção das identidades e os estereótipos fazem parte da dinâmica complexa de codificação dos papéis e comportamentos. Considerando que mesmo a atividade mental - individual - só existe como "orientação social de caráter apreciativo" (Bakhtin, 1995 [1930], p. 114), isto é, tem as interações sociais como sua matéria, a oposição entre as representações sociais (incluídos aqui os estereótipos) e as identidades concretas de indivíduos e grupos não se sustenta.

Para Tessa Perkins, argumentar que os estereótipos são falsos equivale a argumentar que definições socialmente aceitas dos sujeitos não têm efeito sobre eles, isto é, não têm impacto no modo como, concretamente, percebem a si mesmos e interagem com outros indivíduos. Para ela, é mais adequado entender os estereótipos como uma "combinação de validade e distorção" (Perkins apud Seiter, 1986, p. 66). Em outras palavras, não existe necessariamente uma oposição entre as distorções que os estereótipos envolvem e o modo como as experiências dos indivíduos se organizam concreta e efetivamente. Se há tensões, essas devem ser entendidas como parte das continuidades entre os estereótipos e as interações sociais concretas, nas quais as distorções tomam a forma de interpelações para que os indivíduos ajam de uma determinada forma ou enquadrem o próprio comportamento, e os comportamentos dos outros, nos esquemas fornecidos pelos padrões estereotípicos.

Estereótipos e realidade alimentam-se um do outro, confirmando papéis, comportamentos e valores socialmente produzidos. Para voltar aos exemplos de gênero, a análise crítica de estereótipos que vinculam a "natureza" da mulher a determinados espaços, como a casa, e a atividades específicas, como o cuidado com os filhos e outros familiares, pode ter como estratégia a demonstração da falsidade desses estereótipos - mostrando, por exemplo, como a experiência efetiva de muitas mulheres não coincide com eles. Mas, para que seja produtiva, teria que considerar por que razão há, também, identificação. 
Um caminho é, portanto, considerar que os estereótipos não são capazes de dar sentido à totalidade das experiências, mas funcionam como uma interpelação concreta para que os indivíduos e grupos (no exemplo dado, as mulheres), a cada geração, orientem seu comportamento de acordo com esses padrões, confirmando as habilidades aí envolvidas ${ }^{6}$. Internalizadas, as imagens estereotípicas produzem padrões reais de comportamento que confirmam, potencialmente, os estereótipos. Estes passam, assim, a coincidir com aspectos constatados e verificáveis da realidade. O conflito dos indivíduos com os papéis que são chamados a desempenhar pode aparecer, então, como um desvio, em vez de ser tomado como confirmação de que a realidade é mais complexa do que a tipificação.

O impacto dos estereótipos na conformação das identidades depende, nesse caso, de que diferentes indivíduos sejam identificados e valorizados numa escala comum de valores. As caracterizações e julgamentos são relativos, constroem-se em contextos sociais concretos e estão fundados em valores que se pretendem universais ou, ao menos, amplamente compartilhados - com base neles, definem-se, concomitantemente, norma e desvio. Além de ser "viciada", a relação entre estereótipos e realidade está ligada, assim, aos exercícios do poder, com graus variados de institucionalização, que impõem ônus e desvantagens materiais e simbólicos a alguns grupos sociais. A reprodução dos estereótipos pode estar relacionada a formas de opressão que reforçam "constrangimentos e barreiras cotidianas que agem sobre certos grupos” (Young, 1990, p. 54). Não se esgota no reforço a presunções, hábitos e comportamentos, mas pode favorecer a reprodução "das condições materiais e ideológicas que tornam a vida mais fácil, proporcionam mais oportunidades reais e estabelecem a prioridade do ponto de vista dos homens brancos heterossexuais" (Young, 1990, p. 197).

Os estereótipos são mobilizados nas práticas que definem cada uma das faces da opressão consideradas por Iris Marin Young (1990, p. 48-63)7 . A

\footnotetext{
A reprodução dos papéis sociais de gênero está associada, ao mesmo tempo, ao insulamento das mulheres em determinados espaços e ao incentivo ao desenvolvimento de habilidades que confirmam seu pertencimento a esses mesmos espaços. Há, nesse sentido, uma correção (e não um desvio) nos estereótipos, garantida pela própria dinâmica social de reprodução dos papéis - no exemplo dado, os de gênero, como expõem algumas das observações presentes na análise de Chodorow (1999 [1978]). A autora considera cinco faces da opressão: a exploração, a marginalização, a ausência de recursos de poder (powerlessness), o imperialismo cultural e a violência. Em todos os casos, há uma compreensão de que a opressão se produz estruturalmente, constituindo normas, valores e instituições.
} 
atribuição de capacidade diferenciada para o exercício de determinadas funções, dependendo do sexo, da cor, da origem social ou nacional dos indivíduos, as formas de dominação cultural, assim como a vulnerabilidade de alguns grupos à violência - aspectos certamente distintos da opressão, mas que podem sobrepor-se - são situações em que a compreensão estereotipada dos grupos sociais tem efeitos concretos sobre as oportunidades e restrições por eles experimentadas. A relação entre as duas últimas, dominação cultural e vulnerabilidade à violência, é particularmente interessante para esta discussão.

O “imperialismo cultural”, como o define a autora, corresponde à promoção dos significados dominantes numa sociedade, tornando alguns grupos ao mesmo tempo invisíveis e estereotipados. A invisibilidade está relacionada ao fato de que suas perspectivas sociais são silenciadas. Aparecem pela ótica de outros grupos, em estereótipos que os "confinam a uma natureza que é frequentemente vinculada de algum modo aos seus corpos” e que é difícil de ser contestada:

Esses estereótipos permeiam a sociedade de um modo que faz com que não sejam percebidos como algo que pode ser questionado. Assim como todos sabem que a terra gira em torno do sol, todos sabem que os gays são promíscuos, que os índios são alcoólatras e que as mulheres são boas com as crianças. Homens brancos, por outro lado, por escaparem das marcas de grupo, podem ser indivíduos. (Young, 1990, p. 59)

A relação entre essas marcas e a vulnerabilidade à violência é, como se disse, significativa. Para a autora, o que torna a violência uma das faces da opressão não são atos particulares, mas um contexto social que a torna possível e aceitável. A construção da identidade estereotipada de determinados grupos sociais faz com que a violência contra eles seja tolerável e se torne uma "possibilidade constante no horizonte da imaginação social” (Young, 1990, p. 62-63).

Alguns fatores precisam ser considerados na análise dos estereótipos: (a) a relação entre estereótipos, formas específicas de autoridade e hierarquias existentes em um dado contexto social; (b) a relação entre estereótipos, constrangimentos seletivos (que se impõem a alguns grupos, e não a outros) e violência focada em indivíduos com perfis definidos; (c) a capacidade que os diferentes grupos têm de fazer circular, e mesmo de institucionalizar, estereótipos em discursos que confirmam padrões morais de julgamento. 
O foco se volta, assim, para a compreensão de como, e em que circunstâncias, o caráter facilitador e simplificador dos estereótipos coincide com formas opressivas de rotulação e de diferenciação entre padrões normais e desviantes. Fatores como simplicidade, reconhecimento imediato e referência implícita a consensos presumidos sobre os atributos de indivíduos e grupos (Perkins apud Seiter, 1986, p. 66), que constituem os estereótipos, têm seu sentido definido em relações de poder concretas.

Os estereótipos contribuem para a produção, conflitiva e simultânea, da identificação por outros, da distinção e da identidade. Podem, assim, confirmar e reproduzir vantagens, desvantagens e vulnerabilidades, expressas em posições de poder relativas. Ainda que estereótipos, preconceitos e formas de discriminação não possam ser tomados como um único fenômeno ${ }^{8}$, há um continuum entre uns e outros na produção social das identidades tipificadas dos grupos e indivíduos. Nesse sentido, "os estereótipos podem promover a discriminação, influenciando sistematicamente as percepções, interpretações e julgamentos, mas podem também derivar de e ser reforçados por formas de discriminação, justificando disparidades entre os grupos sociais" (Dodiveo, Hewstone, Glick e Esses, 2010, p. 7).

Consideramos, assim, que os estereótipos são artefatos morais e ideológicos que têm impacto para a reprodução das relações de poder. Neles, o caráter moral dos valores e julgamentos está atrelado aos dispositivos ideológicos de legitimação de papéis e posições em uma dada ordem social. Os estereótipos correspondem à definição do outro e do contexto em que as relações se travam em termos de expectativas sociais padronizadas que, por sua vez, pressupõem valores. O próprio conceito de papel social pode ser entendido como um conceito moral, no sentido de que envolve atributos, direitos e deveres determinados; a noção de desvio é, igualmente, uma ideia moral (Newman, 1975, p. 209-210).

Mas se é possível sustentar sem maiores ressalvas o caráter moral dos estereótipos, destacando sua relação com valores socialmente compartilhados e seu papel na distinção entre padrões legítimos e desviantes, entre comportamentos e traços apreciados e desvalorizados, é preciso ter mais cuidado ao defini-los como artefatos ideológicos.

Podem ser entendidos como três formas de atitude social "enviesada" contra um grupo e os indivíduos que dele fazem parte. Os estereótipos corresponderiam a "associações e atribuições de características específicas a um grupo"; os preconceitos corresponderiam a "uma atitude que reflete uma avaliação abrangente de um grupo"; e a discriminação corresponderia a "comportamento enviesado relativo a, e no tratamento de, um grupo ou seus membros" (Dodiveo, Hewstone, Glick e Esses, 2010, p. 5). 
Uma primeira alternativa, nesse ponto, seria afirmar que são ideológicos porque equivalem a formas de codificação da realidade que colaboram para legitimar a ordem social vigente, ou alguns dos seus aspectos. O problema é que essa afirmação poderia levar ao entendimento de que os estereótipos são mobilizados apenas por quem está em posição social vantajosa, contra ou em desfavor daqueles que são mais vulneráveis socialmente. Parece-nos, diferentemente, que podem ser mobilizados também como uma espécie de contraface do exercício continuado do poder. Ainda que a eles não corresponda, necessariamente, uma crítica consistente às bases da dominação, sua existência nos leva a reconhecer que os significados atribuídos às relações e papéis variam e não reproduzem, necessariamente, a posição de poder objetiva dos grupos. Para tomar dois exemplos conhecidos e mesmo banais, o machão ignorante e incapaz de fazer valer a autoridade que propagandeia e o americano sem sofisticação e conhecimento estão nas piadas e mesmo nos programas humorísticos televisivos. O político ladrão é tão comum, como tipo que habita comentários, críticas cotidianas e piadas, quanto são raras ou restritas as críticas às bases da concentração do poder nos regimes democráticos, mas não deixa de ser, igualmente, um índice de que a subversão das hierarquias faz parte da dinâmica de produção e reprodução social dos estereótipos.

Podemos ampliar, então, a definição da relação entre estereótipos e poder. Os estereótipos remetem às relações de poder, mas em diferentes sentidos: confirmando-as ou demonstrando que as perspectivas daqueles em posição de desvantagem podem não coincidir com as dos poderosos. Considerar os estereótipos desse prisma significa chamar a atenção não apenas para as redes de poder que produzem valores e identidades segundo sua gramática, isto é, segundo a gramática da própria opressão, mas também para as fissuras existentes nas relações de dominação, com a observação das práticas e dos discursos elaborados por aqueles que estão em situação de desvantagem.

Existem, assim, tensões e contradições entre os discursos elaborados pelos dominantes, que são publicamente dispostos como o entendimento legítimo das relações de poder, e aqueles que são produzidos pelos subordinados em espaços sociais restritos e relativamente independentes, nos quais estão protegidos do olhar daqueles que lhes são hierarquicamente superiores (Scott, 1990). Essas tensões podem ser a base para o questionamento da noção de falsa consciência, expondo o convívio entre o exercício do poder 
e a subversão, a dissidência e a produção e circulação de discursos alternativos, isto é, que não fazem parte do repertório dos sentidos que respaldam as relações de opressão?.

Para o problema aqui discutido, das relações entre estereótipos, mídia e exercícios de poder, essa análise remete a pelo menos uma questão que nos parece fundamental: a mídia de grande circulação tem impacto para a compreensão da realidade pelo público, mas não contém todos os discursos socialmente relevantes em um dado momento. Mesmo que se pudesse, hipoteticamente, trabalhar com a ideia de que todo o discurso midiático converge na propagação de alguns estereótipos, desvantajosos para determinados indivíduos e grupos, haveria ainda outros discursos, possivelmente com tipificações alternativas, em outros circuitos de comunicação. E isso leva a supor que as contradições existem mesmo quando o discurso midiático estiver internamente livre delas.

O que torna complexa a análise, no entanto, é que é preciso considerar, de um lado, as fissuras dos discursos hegemônicos e, de outro, as condições desiguais para sua produção e circulação. Considerar apenas uma dessas realidades pode levar a uma compreensão equivocada de como os estereótipos se reproduzem. Os recursos para fazer circular os discursos e para posicioná-los e atribuir-lhes peso social não estão igualmente disponíveis a ricos e pobres, homens e mulheres, negros e brancos. Alguns grupos sociais, ou segmentos desses grupos, detêm os meios para divulgar ampla e positivamente seus valores e marcar negativamente outros grupos ou coibir a propagação de outros valores. Se, como mencionamos há pouco, a mídia de grande circulação não contém todos os discursos socialmente relevantes em um dado contexto, não é possível deixar de lado o fato de que os discursos que ela faz circular têm, potencialmente, um peso maior do que aqueles que são produzidos em outros espaços - no âmbito de comunidades localizadas ou mesmo da chamada mídia alternativa - e que é mesmo impossível definir a fronteira entre os discursos produzidos na mídia e aqueles que são produzidos em espaços "não-midiáticos".

\footnotetext{
Os estereótipos podem fazer parte das formas cotidianas de resistência, tais como analisadas por James C. Scott (1990) ao considerar a ressignificação das hierarquias, pelos dominados, em rumores, piadas, canções, provérbios e eufemismos. Podem ser, nesse sentido, parte das evidências de que "o libreto da elite para as hierarquias de nobreza e respeito não é, na realidade, cantado palavra por palavra pelos que a estão sujeitos a elas" (Scott, 1985, p. 41).
} 
Afastando a noção de falsa consciência e, portanto, deixando de lado as definições de ideologia mais próximas da ideia de ilusão e manipulação, é possível aproximar os conceitos de estereótipo e ideologia sem recorrer à oposição entre veracidade e falsidade. É possível aproximá-los, também, evitando o risco de compreender a hegemonia como elisão da resistência. A partir de algumas das abordagens correntes de ideologia, os estereótipos podem ser entendidos como artefatos ideológicos no sentido de que são expressões de uma "versão da realidade social" que é suficientemente real e reconhecida para que não seja simplesmente rejeitada (Eagleton, 1997 [1991], p. 27). Sua realidade estaria em seus efeitos reais, mesmo quando em sua base estão mentiras e visões parciais que são transmutadas em fatos de validade universal ${ }^{10}$.

É possível aproximar os dois conceitos também quando se trata de observar como se dá o trânsito entre o específico e o universal. A compreensão da ideologia como a "matéria da qual cada um de nós é feito, o elemento que constitui nossa própria identidade” e que não é colocado em questão porque se apresenta como óbvio e sabido por todos, remete, novamente, ao problema da construção social das identidades. O discurso ideológico apresenta-se como verdade universal que não precisa ser submetida à análise racional (Eagleton, 1997 [1991], p. 28). E os estereótipos se alimentam da ausência de análise racional dos valores que os estruturam. Apresentados como caracterizações fundadas empiricamente, derivadas da constatação da "natureza" específica dos indivíduos e dos grupos sociais estereotipados, não aparecem como julgamentos, mas como imagens de caráter descritivo.

Tomadas essas definições, a melhor forma de lidar com os discursos ou enunciados ideológicos não parece ser questionar sua veracidade ou falsidade, propondo-se a distinguir entre elas, mas compreender que esses discursos, com seus componentes empíricos e normativos, são parte dos esforços para a "legitimação de certos interesses em uma luta de poder"

\footnotetext{
10 A compreensão da ideologia como interpelação, presente em Louis Althusser (2003 [1971]), permitiria avançar nesse paralelo entre o conceito de ideologia e o de estereótipo. Para o autor, "a existência da ideologia e a interpelação dos indivíduos enquanto sujeitos são uma única e mesma coisa" (Althusser, 2003 [1971], p. 97). Nisso consiste a tensão entre a constituição das identidades (a constituição dos indivíduos como sujeitos) e a sujeição (a ocupação de posições previamente estabelecidas nas relações de poder), resumida na conhecida formulação de que "os sujeitos se constituem pela sua sujeição" (Althusser, 2003 [1971], p. 104). Agradeço a Luis Felipe Miguel pela indicação da proximidade entre os argumentos aqui presentes e essa compreensão em Althusser.
} 
(Eagleton, 1997 [1991], p. 28). Os estereótipos podem ser compreendidos como parte dessa mesma dinâmica, atendendo à lógica mencionada, na qual distorção e validade caminham juntas, desde que se leve em consideração que há conflitos, contradições e dissonâncias na sua produção e circulação.

O questionamento do papel da mídia na difusão e reforço dos estereótipos é, em si mesmo, um exemplo das tensões e formas de mal-estar decorrentes. Os conflitos em torno da ressignificação dos papéis, da redistribuição de recursos e do reconhecimento de grupos e práticas sociais passam, frequentemente, pelo questionamento dos estereótipos ativos em uma sociedade. Isso é, por si só, um índice de que há circuitos variados de comunicação, que não se restringem à grande mídia e aos discursos hegemônicos ${ }^{11}$. O reconhecimento do peso e da centralidade da mídia empresarial convencional nos fluxos comunicativos nas sociedades contemporâneas reforça, porém, a necessidade de entender se e como a mídia faz parte da dinâmica de produção e reprodução dos estereótipos.

\section{Estereótipos e mídia}

O objetivo desta seção é avançar na discussão sobre as relações entre mídia e estereótipos, pensados a partir das definições propostas anteriormente neste artigo e, sobretudo, a partir dos problemas e questões que elas nos colocam. As considerações aqui tecidas sobre o funcionamento da mídia pretendem funcionar como uma base para a crítica à dualidade entre mídia/superação dos estereótipos e mídia/propagação dos estereótipos.

A partir do que foi discutido na seção anterior, parece claro que os estereótipos não podem ser entendidos como originários da mídia ou das formas de sociabilidade reorganizadas pelo advento dos meios técnicos de difusão massiva. Alguns estudos afirmam justamente o contrário (Meyrowitz, 1985).

Mas a presença dos estereótipos no discurso midiático pode colaborar para seu impacto e permanência. Difundidos para um grande número de pessoas, transformam-se em referências compartilhadas que fazem parte, simultaneamente, da experiência individual e social. Permitem, por exemplo, que um determinado comportamento ou bordão seja referência comum a

\footnotetext{
Setores do movimento negro no Brasil têm centrado atenção nos estereótipos racistas presentes na mídia. Apesar de não ser possível discutir este tópico neste artigo, parece relevante indicar que, ao mesmo tempo, as estratégias de reconhecimento mobilizadas pelos movimentos recorrem também a estereótipos (que ganham, no entanto, sinal positivo), constituindo identidades relativamente fundadas justamente em critérios de diferenciação étnico-raciais (cf. Guimarães, 2002; Neves, 2005).
} 
indivíduos que nunca tiveram contato direto e estão posicionados socialmente (por classe, ocupação, sexo, raça, idade) de maneiras diversas. $\mathrm{Na}$ mídia, a caracterização de eventos e indivíduos distantes a partir de discursos moralmente codificados é associada a narrativas familiares, que organizam a cobertura noticiosa.

Os meios de comunicação têm, nas sociedades contemporâneas, um papel central na difusão de representações do mundo social. A relação com o mundo é mediada por imagens produzidas e difundidas em escala industrial, fazendo com que nossas referências sejam uma fusão entre o mundo com o qual temos contato diretamente e o mundo que conhecemos pelas telas da TV, pela internet e pelas páginas de revistas e jornais. Dessa perspectiva, é preciso pensar na complementaridade entre diferentes modalidades de relação com o mundo, mas também na dependência cognitiva dos indivíduos em relação aos meios de comunicação nas sociedades midiatizadas. Mais do que julgar o que a mídia nos oferece pela realidade direta que nos estaria à mão, orientamo-nos por um conjunto de informações cuja relevância e pertinência não podemos, na maior parte das vezes, medir sem recorrer à própria mídia. Isso vale, especialmente, para os eventos, esferas e indivíduos com os quais temos contato apenas pela mídia.

Mas a distância física - e o conhecimento limitado - dos objetos e atores estereotipados não é condição sine qua non para que os estereótipos se reproduzam. Não lidamos com imagens estereotipadas porque não tivemos acesso à "natureza real" das coisas e dos indivíduos" ${ }^{12}$. Há um continuum entre o desempenho cotidiano dos papéis atribuídos aos grupos sociais e os padrões que definem valores e expectativas que estão na base da avaliação desse desempenho. Em outras palavras, as relações e circunstâncias que nos são próximas também são investidas de sentidos definidos por expectativas sociais padronizadas.

Nas relações de gênero, por exemplo, os estereótipos organizam as expectativas quanto ao papel de mulheres e homens nas relações afetivas, profissionais e políticas, "contaminando" as diferentes esferas. Fundados

\footnotetext{
2 Essa compreensão é muito comum na literatura infantil contemporânea progressista. Um exemplo bastante característico pode ser encontrado na história de Cláudia Fries (2000 [1999]), sobre o momento em que os moradores de um prédio, uma galinha, uma raposa e um coelho, ganham um novo vizinho, um porco. O estereótipo é superado quando os moradores têm acesso à verdade sobre os fatos relacionados ao novo morador, o que corresponde, nesse caso, à assimilação do "outro" aos padrões normativos de referência.
} 
em definições do papel adequado da mulher na esfera doméstica, os estereótipos de gênero permeiam outros espaços e interações, impondo limites a sua atuação: esse é um dos sentidos da afirmação de que a conexão entre os aspectos doméstico e não-doméstico da vida é profunda (Okin, 1989, p. 126). A caracterização de indivíduos em situações próximas e íntimas se dá, assim, a partir de expectativas sociais padronizadas - a especificidade de uma relação conjugal não impede, por exemplo, que o comportamento daquela "esposa" seja avaliado relativamente ao estereótipo socialmente predominante da "boa mãe" (no exemplo dado por Goffman, 2008 [1963], p. 63) ou, inversamente, que a atuação de uma "profissional" seja também avaliada a partir de pressupostos sobre como se comportam "as mulheres", fundados em estereótipos que as vinculam à domesticidade ${ }^{13}$.

Nos dois casos - o da avaliação do que nos é familiar a partir de expectativas sociais padronizadas e o da avaliação de espaços e atores com os quais não temos contato direto a partir das formas assumidas pelas interações sociais na vida cotidiana e na esfera doméstica -, a reprodução dos estereótipos corresponde à naturalização de características e competências. Pode corresponder, ainda, à naturalização do pertencimento distinto dos indivíduos aos diferentes campos sociais. Os meios de comunicação participam desse processo de naturalização dos pertencimentos e das exclusões.

A centralidade dos meios de comunicação nas sociedades contemporâneas está relacionada ao fato de que nossa experiência é hoje, em grande parte, mediada por aparatos técnicos que difundem conteúdos de forma massiva. O acesso a informações sobre eventos que não presenciamos e o compartilhamento de referências entre indivíduos que se desconhecem mas que têm acesso aos mesmos conteúdos midiáticos - estão no centro da experiência social contemporânea.

A análise da formação das opiniões e das preferências nesse contexto de desenvolvimento dos meios técnicos de comunicação levou a considerar, detidamente, como a relação entre a percepção dos indivíduos e os fatos era impactada pela propaganda e pelas informações difundidas pela mídia. A

\footnotetext{
${ }^{3}$ É comum que a avaliação da competência das mulheres para a política seja fundada nas expectativas e padrões convencionais que organizam os papéis na esfera doméstica (como expõem Bystrom, Banwart, Kaid e Robertson, 2004; lyengar, Valentino, Ansolabehere e Simon, 1997; Kahn, 1996; Miguel e Biroli, 2011). A avaliação das habilidades de mulheres e homens para a política parece ser parte dessa dinâmica complexa em que os estereótipos são confirmados ou contestados a partir de referências pertencentes a diferentes "camadas" da experiência.
} 
afirmação de que as "imagens internas", feitas de "preconceitos e prejuízos que interpretam, preenchem e dirigem poderosamente o transcurso de nossa atenção e de nossa visão" colocam-se entre os indivíduos e o mundo externo (Lippmann, 2008 [1922], p. 41) é um dos patamares a partir do qual se definiram as análises contemporâneas sobre as relações entre a mídia e a produção das opiniões.

A visão dos fatos depende de "onde estamos posicionados e dos hábitos de nossos olhos" (Lippmann, 2008 [1922], p. 84), mas os olhos seriam crescentemente habituados pela própria mídia, influenciando a maneira como os indivíduos entendem e reconhecem sua posição no mundo. Esse é um caminho para a presunção de que existe uma correlação direta entre o que os meios de comunicação produzem e veiculam e como pensarão as pessoas que estão expostas a eles. Em outras palavras, para uma relação de causalidade entre os conteúdos difundidos pela mídia e as formas assumidas pela opinião pública.

Essa compreensão tem convivido com teses e argumentos que a confrontam. As reações críticas à chamada teoria hipodérmica estão entre eles. Um aspecto importante, já considerado pelo próprio Lippmann, é que o público não responde aos conteúdos midiáticos de forma direta e pré-determinada. A recepção não é, dito de outro modo, determinada pela emissão, ainda que seja necessário pensar na influência desta sobre aquela. Isso se dá, entre outras razões, porque as relações entre os meios de comunicação e seu público não podem ser isoladas de uma série de influências e variáveis que compõem o horizonte cognitivo e político dos indivíduos.

Nossas pré-concepções são formadas por um conjunto complexo de referências disponíveis, entre as quais estão aquelas fornecidas pelos discursos midiáticos. É preciso considerar pelo menos dois fatores: o primeiro é que as informações e imagens disponibilizadas pela mídia ganham sentido relacionadas a um conjunto de outras informações e imagens acumuladas ao longo da trajetória dos indivíduos, isto é, são decodificadas em seu ambiente próximo, em processos cognitivos que são marcados por sua posição social. Isso nos obriga a lembrar que se o conteúdo midiático é, em larga medida, produzido de forma concentrada e homogênea, a recepção é sempre localizada e socialmente posicionada (Thompson, 2002 [1990]).

O segundo fator, na consideração da complexidade da relação entre a mídia e o público, é que o discurso midiático, ainda que tenha um alto 
grau de homogeneidade, não é ordenado de modo coerente. Há posições e imagens conflitantes sendo difundidas pelos meios de comunicação simultaneamente - e esses meios de comunicação não são um bloco indistinto. Além disso, o efeito do que é difundido depende dos segmentos do público que a ele estão expostos, em suas variações socioeconômicas, de gênero, de raça, de faixa-etária, no nível educacional, nas crenças e afiliações religiosas, local de habitação, padrões das relações familiares, entre outros aspectos ${ }^{14}$.

Isso não significa deixar de lado a assimetria entre a produção/difusão e a recepção dos conteúdos de mídia. Não significa, também, diminuir a importância da concentração da propriedade dos meios de comunicação e das rotinas profissionais do jornalismo na padronização dos conteúdos midiáticos e, em especial, dos noticiários. O ponto é que disso não decorre um conjunto de imagens e informações que convergem em um único entendimento ou visão de mundo, nem disso se pode presumir um impacto-padrão dos conteúdos veiculados sobre os diferentes segmentos do público ${ }^{15}$.

Novamente, é preciso considerar os matizes, sem perder de vista o peso que a mídia tem na conformação das representações compartilhadas do mundo social. Os conteúdos não são homogêneos mesmo na mídia empresarial (na chamada "grande imprensa"), os circuitos de comunicação são complexos (não se restringindo, portanto, ao que a "grande imprensa" coloca em circulação em produzindo ruídos e conflitos que têm impacto sobre os processos de significação da realidade social) e, por fim, a recepção é ativa, não permitindo que se considerem as opiniões do público como meros reflexos dos discursos da mídia. Mas isso não elimina, entre outras coisas, a

\footnotetext{
${ }^{14}$ Para uma análise que procura discutir a complexidade da relação entre os meios de comunicação e a produção das opiniões, cf. Biroli e Miguel (2011).

${ }^{15}$ É preciso ter cuidado, nesse sentido, com o que é pressuposto quando se considera que, porque as empresas de comunicação têm posição e interesses econômicos semelhantes, os conteúdos produzidos refletem diretamente essa posição e esses interesses. Mesmo considerando que os valores capitalistas e a incitação ao consumo estão na base do modo de produção e circulação dos conteúdos midiáticos - ou, em outro ângulo mas ainda com o mesmo entendimento, que os meios de comunicação são um elo da dinâmica de consumo nas sociedades contemporâneas -, a compreensão dos meios de comunicação como instrumentos dos interesses econômicos hegemônicos pode deixar de lado a complexidade das disputas simbólicas e os matizes e conflitos entre as posições relativas a tópicos e interesses variados. Um exemplo é a relação da mídia brasileira de grande circulação com tópicos como o papel do Estado na economia (em que há um alto grau de convergência nos noticiários) e com tópicos como as orientações religiosas para o comportamento sexual e o controle reprodutivo (em que há variações e matizes que devem ser considerados). A não ser que se presuma que um desses tópicos é mais relevante do que o outro, não é justificável definir o comportamento e os discursos dos meios de comunicação apenas a partir de um deles.
} 
dependência cognitiva dos indivíduos em relação aos meios informativos. As relações que estabelecemos com algumas esferas da vida em sociedade consistem, quase inteiramente - e sistematicamente -, em contatos mediados pelos aparatos técnicos de comunicação, com destaque para o jornalismo em alguns casos, como o da política. Para a maior parte das pessoas, "a política", isto é, um modo restrito de compreensão da política que a reduz, grosso modo, ao Estado, é aquilo que é visível midiaticamente.

A teoria do agenda setting, em suas diferentes versões, procurou dar conta justamente do fato de que os meios de comunicação podem não ser capazes de definir como os indivíduos pensam, determinando suas opiniões e preferências. Mas definem, em grande medida, os temas sobre os quais eles pensam. Nesse sentido, fica difícil estabelecer fronteiras entre o que é socialmente relevante para os cidadãos em um dado momento e o que a agenda da mídia torna saliente. A hipótese, nesse caso, é que existe uma correlação significativa entre relevo nos meios de comunicação e relevância para o público.

Procurando analisar os diferentes aspectos dessa correlação, Maxwell McCombs (2009 [2004]) define dois tipos de agendamento: temático e de atributos. Partindo de suas observações, fundadas em um conjunto variado de pesquisas empíricas sobre o impacto dos discursos midiáticos sobre o público, podemos entender que: (1) a agenda da mídia tem impacto na definição da agenda do público; (2) esse impacto corresponde ao compartilhamento de temas, mas também de formas de caracterização e valorização desses temas; e, por fim, (3) a agenda temática é inseparável dos enquadramentos que organizam o acesso aos temas, isto é, das molduras que tornam os temas visíveis em uma narrativa que lhes dá sentido.

A definição dos enquadramentos como esquemas simplificadores e como atalhos cognitivos permite aproximá-los das definições do conceito de estereótipo antes propostas. Nos dois casos, a tipificação está ancorada em referências compartilhadas, sem as quais não teria efeito. E, nos dois casos, o recurso repetido a essas referências corresponde a sua atualização, isto é, ao reforço a determinadas formas de enquadrar eventos, dar sentido a relações de causalidade e caracterizar indivíduos e grupos sociais. Além disso, o entendimento corrente da noção de enquadramento desloca a ideia de manipulação, dando ênfase para os pressupostos que organizam o mundo para os jornalistas e para o público, permitindo que um evento "novo" ganhe 
sentido em narrativas relativamente estáveis, já cristalizadas. Os fatos ganham saliência em uma causalidade e segundo definições e valorações cristalizadas ${ }^{16}$.

Não é de nosso interesse, no entanto, concentrar esta discussão no conceito de enquadramento, mas no fato de que o jornalismo consiste em um conjunto relativamente restrito de padrões narrativos cristalizados. $\mathrm{O}$ conceito de enquadramento está entre aqueles que procuram dar conta desse aspecto da produção jornalística. O noticiário é produzido dentro do limites de convenções, como aquelas que estão na base dos rituais da objetividade definidos por Gaye Tuchman (1992) e a partir de recursos de sentido restritos e compartilhados, isto é, de um leque restrito de discursos de referência. $\mathrm{Na}$ base dos procedimentos rotinizados estão padrões morais que o jornalismo contribui para reproduzir. A “objetivação dos padrões morais" (Ettema e Glasser, 1998, p. 62) é uma face importante da cobertura noticiosa, pressupondo, como se disse, valores e não apenas referências comuns. E esses valores não são apenas reforçados, mas reacomodados ou reativados quando estão na base da leitura que é feita de situações novas, de uma realidade em transformação (Ettema e Glasser,1998, p. 63).

É nesse sentido que os estereótipos são peça-chave para que essas narrativas cristalizadas tenham eficácia. As imagens tipificadas dos grupos sociais permitem mobilizar, mais do que referências comuns, julgamentos que, compartilhados, dão sentido aos acontecimentos. Os enquadramentos e os estereótipos que lhes dão sustentação se exprimem por meio de códigos morais relativamente estáveis. Ao colocá-los mais uma vez em circulação, o jornalismo contribui para essa estabilidade.

A atribuição de status aos atores e a estereotipia, entendida como construção da imagem que envolve a saliência de atributos, são também dois aspectos do agendamento em seu sentido mais amplo (McCombs, 2009 [2004], p. 135), entendido como saliência de temas que se tornam visíveis em caracterizações e enquadramentos definidos. A seleção das temáticas presentes no noticiário envolve, assim, o recurso a narrativas por meio das quais essas temáticas fazem sentido. É razoável, por tudo que foi dito anteriormente so-

\footnotetext{
${ }^{16}$ Entendo que a aproximação entre estereótipos e enquadramentos permite desenvolver essa discussão para além dos seus limites neste texto. Os argumentos aqui presentes foram se definindo, preliminarmente, a partir da leitura da obra Goffman. Ainda que de maneira indireta, esta discussão é tributária das reflexões do autor em Estigma (2008[1963]) Frame analysis (2006[1975]) e A representação do eu na vida cotidiana (2009[1959]). Para um conjunto variado de análises que recorre a esse conceito, assim como discussões sobre seus limites e potenciais, sugiro a leitura de Callaghan e Schnell (2005).
} 
bre estereótipos e enquadramentos, que essas narrativas atendam a padrões simplificadores e que estes, por sua vez, envolvam rotulações e distinções. Isso está menos relacionado a formas de manipulação ou distorção estrategicamente impetradas do que aos discursos e estereótipos "disponíveis" - que ganham peso e legitimidade em uma configuração específica das relações de poder $e$ das práticas jornalísticas, em um dado contexto.

O noticiário é feito a partir de escolhas que estão implícitas nas rotinas jornalísticas. Acompanhando a análise de Timothy Cook (1998), essas escolhas são reproduzidas "naturalmente" porque: (a) os jornalistas compartilham um mesmo repertório, (b) os jornalistas compartilham um numero restrito de fórmulas na busca das informações e produção dos textos. A seleção dos temas relevantes, que inclui a seleção de quem está capacitado e disponível para falar sobre eles, e sua organização em enquadramentos determinados, são parte dessas escolhas rotineiras. Os estereótipos podem ser fatores de seleção e organização dos sentidos nas duas etapas, seleção dos temas e consolidação dos enquadramentos (separadas apenas para facilitar essa argumentação).

Na primeira, a seleção de temas e personagens pode atender às expectativas-padrão sobre o que é socialmente relevante e quem é habilitado a emitir opiniões sobre aquilo que ganha destaque. Pode-se supor, nesse sentido, que não existe uma fronteira clara entre status e estereótipos, mesmo quando se pensa em cargos e posições institucionais que conferem status àqueles que as ocupam: eles potencializam o que podemos chamar aqui de uma "visibilidade competente", mas não a garantem. Se o acesso às "janelas de visibilidade" (Gomes, 2008) restritas no noticiário político depende de posições institucionais, esse acesso, por outro lado, não garante aos diferentes atores (a mulheres e homens, por exemplo) uma presença equânime no discurso midiático, tanto do ponto de vista quantitativo quanto do qualitativo ${ }^{17}$.

Na segunda etapa, as narrativas que conferem sentido aos temas e personagens ancoram-se significativamente nos estereótipos vigentes. Pode-se assumir que existe uma espécie de "memória compartilhada" entre os jornalistas, que é produto de suas práticas, de sua ética e de sua posição objetiva em relação

\footnotetext{
7 Um exemplo disso é a relação entre mulheres e temáticas consideradas femininas, especialmente aquelas relacionadas à esfera doméstica e à família, no noticiário político. O jornalismo concede mais espaço às mulheres quando elas se encontram próximas de sua esfera tradicional, a dos assuntos privados e do cuidado com os outros, mas a vinculação a tais temáticas as afasta do núcleo do noticiário político (Miguel e Biroli, 2011).
} 
a outros campos. Ela os leva a dar maior atenção a determinados atributos, a destacar alguns aspectos do comportamento dos atores em detrimento de outros, a estabelecer correlações previsíveis entre o evento abordado e outros eventos (em esferas variadas), assim como a definir de maneira relativamente estável os ângulos em que as imagens são produzidas. E parte importante dessa dinâmica consiste na evocação de imagens-típicas para construir narrativas que funcionam como atalhos cognitivos para uma realidade que é complexa.

Isso facilita o trabalho rotineiro dos jornalistas, na medida em que confere previsibilidade e homogeneidade a suas rotinas. Facilita, ainda, a relação entre os diferentes segmentos do público e o noticiário que lhes é apresentado, na medida em que orienta a leitura por meio de padrões que, cumulativa e rotineiramente, constituem as representações do mundo social nas quais suas "novas" leituras de "novos" discursos estarão ancoradas. Mas, como foi dito anteriormente, a tipificação não corresponde, apenas, à simplificação. Pode, também, reforçar obstáculos simbólicos e materiais para indivíduos e grupos estereotipados.

A correlação entre a definição dos temas presentes nos noticiários, as narrativas em que esses temas se inserem e a seleção de quem tem voz nos debates que ganham tempo e espaço nos meios de comunicação está relacionada concomitantemente à simplificação dos processos cognitivos e à reprodução de formas de distinção. Ao ativar compreensões tipificadas da realidade, o jornalismo confirma e ao mesmo tempo promove alguns atores sociais ao lugar de enunciadores privilegiados, isto é, de indivíduos que têm competência e recursos para dizer algo que merece a atenção do público. Por outro lado, reforça, em relação a outros, caracterizações negativas ou pouco vantajosas do ponto de vista da promoção de seu acesso a recursos simbólicos e materiais que podem ser transmutados em uma maior autonomia, em posições de poder e/ou em status.

A agenda da mídia noticiosa é definida a partir de uma combinação de fatores. As rotinas produtivas interagem com a atuação do governo (por meio das assessorias de imprensa e de outras formas de comunicação governamental); com as fontes que têm, individualmente, trânsito entre os jornalistas; com instituições e grupos que procuram tornar eventos e tópicos noticiáveis segundo seus interesses e perspectivas. Não há, sempre, complementaridade. Pelo contrário, a agenda é objeto de disputas. Mas essas disputas não assumem, necessariamente, a forma da oposição entre imagens 
distorcidas e imagens "reais" ou entre estereótipos e caracterizações mais complexas de temas e atores ${ }^{18}$.

O que está em jogo é, portanto, a associação entre as imagens dos atores sociais e a estabilidade relativa dos papéis a eles associados, com as vantagens e desvantagens envolvidas. As tipificações são diversas, mas estão desigualmente presentes nos discursos da mídia. Não consistem, todas elas, em obstáculos à construção autônoma da vida dos indivíduos. Mas pode-se dizer que algumas delas contribuem para a vulnerabilidade de alguns, e a posição socialmente fortalecida e legitimada de outros. O problema, portanto, não está na constatação da presença das narrativas cristalizadas e dos estereótipos que, segundo argumentamos aqui, são centrais à conformação do discurso jornalístico, mas na compreensão de como esses estereótipos funcionam em relações de poder concretas, em contextos determinados.

\section{Conclusão}

O compartilhamento massivo de referências que os meios de comunicação possibilitam pode contribuir para a reprodução dos estereótipos ou para sua reorganização ou superação (em direção a novos arranjos estereotípicos, isto é, a novas expectativas-padrão). Os matizes na presença dos estereótipos, ou no recurso a diferentes estereótipos, não devem, portanto, ser ignorados. Podem ser índices de conflitos e de mudanças - assim como dos limites dessas mudanças - nas sociedades, nos contextos em que os noticiários são produzidos. Nas pesquisas empíricas, a comparação entre o noticiário de diferentes veículos ou entre matérias voltadas para temáticas distintas, em um mesmo momento, ou a comparação do noticiário em diferentes momentos, por meio de séries históricas, pode ser necessária para uma discussão mais complexa dos estereótipos na mídia.

A constatação de que os estereótipos são parte do discurso midiático é, portanto, apenas um ponto de partida. Os estereótipos são peças-chave no discurso jornalístico, que está sob a nossa atenção, em pelo menos dois

\footnotetext{
${ }^{18}$ No caso das mulheres presentes no noticiário político, as pesquisas realizadas indicam que é preciso ter em mente que o fato de que os estereótipos sejam uma via de acesso mais "fácil"ao noticiário - porque não entram em choque com as narrativas e expectativas convencionais - pode levar a estratégias para a conquista da visibilidade que não os confrontam. Isso varia, entre outras coisas, de acordo com o peso que a visibilidade tem para a carreira dos atores específicos em um dado momento. O ponto, no entanto, é que as mulheres políticas podem estar diante de duas alternativas: a exclusão do noticiário ou a inclusão estereotipada.
} 
de seus aspectos rotineiros: a apresentação do novo por meio de atalhos cognitivos, que os coloca como peça de sustentação dos enquadramentos, e a identificação dos grupos sociais a partir de valores e expectativas-padrão supostamente compartilhadas e que não aparecem como objeto de discussão.

Os estereótipos colaboram, assim, para que o noticiário atravesse a complexidade dos processos de formação das identidades sem problematizá-los, ao dispor essas identidades como dados objetivos, a partir de valores morais naturalizados. Neles, como se disse antes neste artigo, o trânsito entre o individual e o universal apenas confirmaria os valores e julgamentos que estão em sua base. Por isso os definimos como artefatos - morais e ideológicos - que atuam simbolicamente e têm efeitos concretos, interpelando os indivíduos ao mesmo tempo em que atualizam julgamentos.

$\mathrm{O}$ fato de que exercem pressão para que a individualidade seja vivenciada segundo determinadas expectativas-padrão não significa que a vivência individual de fato corresponderá a elas, espelhando essas expectativas coerentemente. Mas, como parte da dinâmica de reprodução, acomodação ou deslocamento das relações de poder, os estereótipos interpelam, constituindo as identidades, e constrangem à compreensão dos comportamentos segundo a insígnia da normalidade e do desvio.

As brechas e ruídos existem, mas as dificuldades para que as rupturas com os estereótipos vigentes aconteçam se devem a essa dinâmica - isto é, aos constrangimentos que se associam aos estereótipos. Está em jogo, entre outras coisas, a capacidade que os indivíduos em posições vantajosas (entre outras coisas, de controle dos meios de comunicação ou de acesso a eles) têm para definir as perspectivas válidas nos discursos que, potencialmente, têm maior alcance e legitimidade.

Os estereótipos não são uma simples falsificação, que se oporia à realidade das vivências e da construção das identidades. É possível, por exemplo, sustentar que o aprendizado das identidades sexuais, entre outros aspectos que constituem as identidades, se dá sempre "através de oposições, caricaturas e estereótipos” (Badinter, 2005 [2003]). Mas mesmo que se considere que são, nesse sentido, incontornáveis, a compreensão de quais são esses estereótipos, de como se dá sua reprodução e de quais são seus efeitos nas relações sociais concretas é fundamental. É fundamental, ainda, a compreensão das razões pelas quais alguns deles ganham guarida nos discursos 
da mídia de grande público, enquanto outros podem estar restritos a discursos que têm menor legitimidade social ou a circuitos de comunicação relativamente marginais.

Parece-nos que essas diferenças remetem diretamente à posição dos indivíduos e grupos nas relações de poder e nos campos da produção intelectual e da produção jornalística. Em última instância, o problema dos estereótipos na mídia remete ao problema da pluralidade de enquadramentos e perspectivas que constituem o discurso midiático. Trata-se, assim, de um dos problemas relacionados à concentração do acesso à produção dos discursos que a mídia faz circular.

Os meios de comunicação de massa consistem numa arena na qual estão em disputa representações diversas da realidade social. Estão em disputa, mais precisamente, a validação de valores e julgamentos que estão na base dessas representações. E essa disputa se coloca em vários níveis e graus, daí o fato de que os discursos colocados em circulação pela mídia recorram a tipificações, tenham como efeito potencial a naturalização de determinados estereótipos, mas não se restrinjam a uma versão coerente e linear dos grupos sociais e das relações de poder em que se inserem.

\section{Referências bibliográficas}

ALTHUSSER, Louis. 2003 [1971]. Aparelhos ideológicos do estado. 9a ed. Rio de Janeiro: Graal.

BADINTER, Elizabeth. 2005 [2003]. Rumo equivocado: o feminismo e alguns destinos. Rio de Janeiro: Civilização Brasileira.

BAKHTIN, Mikhail. 1995 [1929]. Marxismo e filosofia da linguagem. São Paulo: Hucitec.

BIROLI, Flávia. 2010. "Gênero e política no noticiário das revistas semanais brasileiras”. Cadernos Pagu, n. 34, p. 269-299.

. 2011. "Mulheres e política na mídia brasileira: estereótipos de gênero e marginalidade do 'feminino' na política”. In: PAIVA, Denise \& BEZERRA, Heloísa Dias. Mulheres, poder e política. Goiânia: Cânone Editorial.

\& MIGUEL, Luis Felipe. 2011. "Razão e sentimento: a comunicação política e a decisão do voto”. Trabalho apresentado no Grupo de Trabalho "Comunicação e Política" do XX Encontro da Compós, Porto Alegre, RS, 14 a 17 de junho. 
BYSTROM, Dianne G.; BANWART, Mary Christine; KAID, Lynda Lee \& ROBERTSON, Terry A. 2004. Gender and candidate communication. New York: Routledge.

CALLAGHAN, Karen \& SCHNELL, Frauke (eds.). 2005. Framing american politics. Pittsburgh: University of Pittsburgh press.

CHODOROW, Nancy. 1999 [1978]. The reproduction of mothering. Berkeley/ Los Angeles: University of California Press.

COOK, Timothy E. 1998. Governing with the news: the news media as a political institution. Chicago: The University of Chicago Press.

DOVIDIO, John F.; HEWSTONE, Miles; GLICK, Peter \& ESSES, Victoria M. 2010. "Prejudice, stereotyping and discrimination: theoretical and empirical overview". In: DOVIDIO, John F.; HEWSTONE, Miles; GLICK, Peter e ESSES, Victoria M. (eds.). The sage handbook of prejudice, stereotyping and discrimination. London: Sage.

EAGLETON, Terry. 1997 [1991]. Ideologia. São Paulo: Editora Unesp.

ETTEMA, James S. \& GLASSER, Theodore L. 1998. Custodians of conscience: investigative journalism and public virtue. New York: Columbia University Press.

FRIEDAN, Betty. 1997 [1963]. The feminine mystique. New York/London: WW Norton.

FRIES, Cláudia. 2000 [1999]. Um porco vem morar aqui! 11ª ed. São Paulo: Brinque Book.

GOFFMAN, Erving. 2006 [1975]. Frame analysis: los marcos de la experiencia. Madri: CIS/Siglo XXI.

. 2008 [1963]. Estigma: notas sobre a manipulação da identidade deteriorada. $4^{\text {a }}$ ed. Rio de Janeiro: LTC.

2009 [1959]. A representação do eu na vida cotidiana. 16 ed. Rio de Janeiro: Vozes.

GOMES, Wilson. 2008. "Mapeando a audioesfera política brasileira: os soundbites políticos no Jornal Nacional”. Trabalho apresentado ao Grupo de Trabalho "Comunicação e Política" do XVII Encontro da Compós, São Paulo, PUC-SP, 3 a 6 de junho.

GUIMARÃES, Antonio Sérgio. 2002. "Democracia racial: o ideal, o pacto e o mito". Classes, raças e democracia. São Paulo: Editora 34.

IYENGAR, Shanto; VALENTINO, Nicholas A.; ANSOLABEHERE, Stephen \& SIMON, Adam F. 1997. "Running as a woman: gender stereotyp- 
ing in political campaigns". In: NORRIS, Pippa (ed.). Women, media, and politics. Oxford: Oxford University Press.

KAHN, Kim Fridkin. 1996. The political consequences of being a woman: how stereotypes influence the conduct and consequences of political campaigns. New York: Columbia University Press.

LIPPMANN, Walter. 2008 [1922]. Opinião pública. Petrópolis, RJ: Vozes.

McCOMBS, Maxwell. 2009 [2004]. A teoria da agenda: a mídia e a opinião pública. Petrópolis, RJ: Vozes.

MEYROWITZ, Joshua. 1985. No sense of place: the impact of electronic media on social behavior. New York/Oxford: Oxford University Press.

MIGUEL, Luis Felipe \& BIROLI, Flávia. 2010. "Visibilidade na mídia e campo político no Brasil”. Dados, v. 53, n. 3, p. 695-735.

.2011. Caleidoscópio convexo: mulheres, política e mídia. São Paulo: Editora Unesp.

MILL, John Stuart. 1991 [1859]. Sobre a liberdade. Petrópolis, RJ: Vozes.

MILTON, John. 1999 [1644]. Areopagítica. Rio de Janeiro: Topbooks.

MUTZ, Diana C. \& MARTIN, Paul S. 2001. "Facilitating communication across lines of political difference: the role of mass media". The American political science review, v. 95, n. 1, p. 97-114.

NASCIMENTO, Milton Meira do. 1989. Opinião pública e revolução. São Paulo: Edusp/Nova Stella.

NEVES, Paulo Sérgio da C. 2005. "Luta anti-racista: entre reconhecimento e redistribuição". Revista Brasileira de Ciências Sociais, v. 20, n. 59, p. 81-96.

NEWMAN, Graeme R. 1975. "A theory of deviance removal". The british journal of sociology, v. 26, n. 2, p. 203-217.

OKIN, Susan Moller. 1989. Justice, gender, and the family. New York: Basic Books.

SCHUDSON, Michael. 1995. The power of news. Cambridge: Harvard University Press.

SCOTT, James C. 1985. Weapons of the week: everyday forms of peasant resistance. New Haven/London: Yale University Press.

1990. Domination and the arts of resistance: hidden transcripts. New Haven/London: Yale University Press.

SEITER, Ellen. 1986. “The 'terms' of women's stereotypes”. Feminist review, n. 22, p. 58-81.

SUNSTEIN, Cass. 2010 [2009]. Rumores: como se difunden las false- 
dades, por qué nos las creemos y qué se puede hacer contra ellas. Buenos Aires: Debate.

THOMPSON, John B. 2002 [1990]. Ideologia e cultura moderna: teoria social crítica na era dos meios de comunicação de massa. Petrópolis: Vozes.

TUCHMAN, Gaye. 1992. "Objectivity as strategic ritual: an examination on newsmen's notion of objectivity". American Journal of sociology, v. 77, n. 4 , p. 660-679.

WOLF, Naomi. 2002 [1991]. The beauty mith: how images of beauty are used against women. New York: Harper Perennial.

YOUNG, Iris Marion. 1990. Justice and the politics of difference. Princeton: Princeton University Press.

\section{Resumo}

Este artigo discute a relação entre mídia e tipificação a partir de uma análise do conceito de estereótipos. A menção aos estereótipos em análises da mídia, de modo mais amplo, e do noticiário jornalístico, em particular, não corresponde, necessariamente, a uma explicitação do que define esse conceito. Também não corresponde a uma análise de suas conexões com outros conceitos comuns aos estudos de mídia, como os conceitos de agenda e enquadramento. Este estudo procura contribuir para uma análise teórica dos estereótipos na mídia, propondo que sejam compreendidos como artefatos morais e ideológicos. As análises aqui presentes expõem os sentidos dessa definição, considerando tensões e ambiguidades presentes nas dinâmicas de reprodução e de superação dos estereótipos no discurso jornalístico.

Palavras-chave: estereótipos; mídia; discurso jornalístico; poder; tipificação.

\section{Abstract}

This paper discusses the relationship between media and the creation of types from the point of view of an analysis of the concept of stereotypes. The mention of stereotypes in media analyses, in a wider sense, and of the news in particular, does not mean necessarily making that concept explicit. It also does not correspond to an analysis of its connections with other current concepts in media analysis, as agenda and framing. This study is a contribution to a theoretical analysis of media stereotypes, understanding them as moral and ideological artifacts. The analyses it includes show the meanings of that definition, taking into account the tensions and ambiguities present in the dynamics of reproduction and overcoming of stereotypes in journalistic discourse.

Key words: stereotypes; media; journalistic discourse; power; creation of types. 